\title{
Review on Methods of Fault Diagnosis in Photovoltaic System Applications
}

\author{
Syafaruddin ${ }^{1, *}$ and Donald S. Zinger ${ }^{2}$ \\ ${ }^{1}$ Department of Electrical Engineering, Universitas Hasanuddin, Jalan Poros Malino Km. 6, Gowa 92171, Indonesia \\ ${ }^{2}$ Department of Electrical Engineering, Northern Illinois University, 1425 W. Lincoln Hwy., DeKalb, Illinois 60115, USA
}

Received 18 June 2018; Accepted 11 October 2019

\begin{abstract}
Recently, detection and identification of faults in photovoltaic (PV) system applications have been attracting researchers worldwide. Some of them have investigated the causes of potential faults, have worked on how to monitor and identify the faults through fault diagnosis, and have elaborated on how to develop problem-solving methods for the early detection of faults in PV system operations. This paper attempts to provide information comprehensively from the previous research. It summarizes types of faults, methods used in early fault identification and monitoring, and PV fault prevention and protection systems. The paper also investigates future trends in PV system fault diagnosis which include real-time implementation. The paper is expected to bring new perspective about the literature associate with fault studies in PV systems. This survey will be beneficial for the future discussion on how to provide comprehensive solutions for PV system fault problems. It will help avoid research repetition on similar topics and focus on the improvement and performance development of PV fault diagnosis methods.
\end{abstract}

Keywords: detection and identification, fault diagnosis, monitoring systems, protection systems, PV systems.

\section{Introduction}

The utilization of solar energy for electricity and heat energy sources has increased significantly over the last decade. More specifically, photovoltaic (PV) systems have established an important role in the electricity energy sectors by contributing more than $10 \%$ electricity energy supply nowadays. There are many reasons that grid connected PV systems are proliferating, such as reasonable cost of installation along with fast energy and investment payback that includes possible incentives to customers. In this case, continuous output energy production needs to be confirmed in order to satisfy the cost benefit analysis of PV installations. Due to high growth of PV system capacity on grid systems worldwide, the PV system technology is getting mature and competitive in the power market. Therefore, the optimization of PV operations in terms of reliability, efficiency and maintenance including the fault management will be the main focus of PV system engineers.

However, like other power generation systems, fault conditions are also inevitable in PV systems and will be one of the main challenges to be solved. Such challenges include how to maintain reliability and reduce power and energy losses of the systems. Faults that might be found in off-grid, on-grid and hybrid power systems can be defined as the failures that occur in the solar cell panel and system components, such as power converters and wiring connections [1]. Faults in PV systems can potentially occur anytime during their operation and are sometimes late to be detected or can remain undetected [2]. The existence of faults like arc faults and ground and phase faults which continue in

"E-mail address: syafaruddin@unhas.ac.id

ISSN: 1791-2377 @ 2019 School of Science, IHU. All rights reserved.

doi:10.25103/jestr.125.07 the system for extended time periods might influence the power and energy output conversion. Such faults could also affect the safety and reliability of the overall system performance.

There are many potential faults that may appear in PV systems. The causes of faults might be accumulated since the PV panel systems are exposed to the harsh open-space environments. An important factor in the life time operational limit is where the solar cell material composing the PV panel undergoes deformation and aging in unexpected conditions. The cause of the aging material problems could be from component interactions, environmental factors and human errors in design, manufacturing, installation and maintenance. In general, PV manufacturers have set the life time operation of PV panels to 25 years, but the output power performance starts degrading before the economical operation time due to faults that frequently occur. It is important to implement aging management schemes in order to reduce downtime, to enhance safety and to increase reliability margins [3].

Careless handling and misconnection of wiring systems during the installation could not be denied as another prominent causes of operational PV system faults. With regards to this point, an incorrect polarity connection of a PV panel output could potentially lead to a short-circuit condition. Likewise, weak wiring joint connections may lead to an opencircuit condition. These types of wiring faults are commonly identified in PV panels. [4]. With the use PV technology increasing, the potential hazards related to these faults need to be decreased. Short-circuit and open-circuit faults are identified as important causes that reduce the output power of PV systems. The inappropriate installation, lack of maintenance, and material aging effects may directly increase the chances of arc fault conditions. If an arc fault unknowingly occurs, it will be dangerous for the building as well as the PV system facilities since it leads to a fire hazard. 
Therefore, it is important to have early warning systems for these faults in order to have safe and reliable electricity supply $[5]$.

All in all, the most discussed causes of potential PV faults are the partial shading of PV modules. Partial shading occurs when some cells receive less intense sunlight compared to others due to sunlight being blocked by building, other objects, or dirty panel surfaces. In this respect, there will be mismatched operation of solar cells where the output performance of individual solar cells in series is not the same. The cells made unhealthy by shading or dirt may block the output of healthy cells leading to the reduction of total output power. Besides the drop in power caused by decreased sunlight, the shading problem can create hot spots that further reduce PV performance and lifetime [6]. In this case, the impact of shading might be reduced by using additional converters optimized for this situation.

Damage to unshaded cells caused by hotspots associated with shaded cells also needs to be considered. For long term operation, the cascading effect of heat surrounding the unhealthy cell will affect the neighbouring cells which could be still healthy. As a result, the solar panel may be totally damaged due to a small hotspot problem caused by faults that occur because of partial shading. Hotspot problems can be identified through non-uniform temperatures appearing in a solar array. To detect this non-uniform surface thermal distribution, the PV module can be scanned using infrared thermography [7]. In this respect, the potential of hot-spot problems can be investigated to improve the reliability of PV systems [8].

Recently, the rooftop installation of solar panels is widely spreading as a part of integrated PV systems. Thermal stress as well as mechanical stresses such as shear and normal stress are potential causes of faults that need to be studied to provide a theoretical basis for PV module reliability [9]. Because PV rooftop installations have limited access for inspection and maintenance, a fault diagnostic method for these systems is compulsory in order to avoid potential faults in every section of the installation [10]. Fires in rooftop building integrated PV systems have occurred because of undetected ground faults found in fuse-based protection systems [11]. Therefore, special attention needs to be given to identification of such faults for accurate and immediate responses. Such responses provide early warning information for anticipating potential severe faults. In addition, concerns about electric shock and fire risk related to rooftop PV system installation, operation and end utilization has been intensively discussed for residential safety purposes [12]. The voltage output from six modules connected in series may cause serious health problems and potential death. Also, potential fire risk could occur from the short circuit conditions. Designing safety standards and guidelines for rooftop PV installations is highly recommended to increase their safety and security.

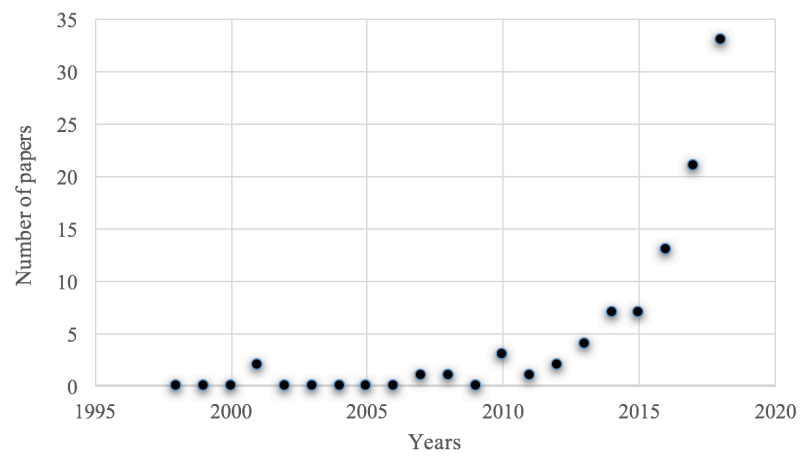

Fig. 1. Previous paper of PV fault studies in scientific literature
Early warning system for fault detection of PV systems may improve their performance in terms of reliability, efficiency and safety. For these reasons, it is highly important to investigate methods available in scientific literature to identify, locate and sort the potential fault locations and determine types and causes of PV faults. A comparison between PV fault detection methods is provided to identify the benefits and drawbacks of real systems from different engineering feasibility points of views and the possible implementation constraints. A large number of methods for PV system fault monitoring, identification and diagnosis have been published in the literature. As shown in Figure 1, there are an exponentially increasing number of publications relate to fault studies of PV systems between 1998 and 2018 indicating it to be one of the hot topics for discussion by PV engineers worldwide.

Fault problems in PV systems can disrupt normal operation and impact the power and energy losses. However, the detection and identification of faults are difficult due to the non-linear characteristic of PV systems. To expect the smooth functioning of PV systems, the common discussion related to the fault diagnostic and identification of PV systems is the methods of detection, type of faults and the fault locations [13]. By investigating previous beneficial studies, this paper summarizes and discusses the various types of PV system faults and their impact (Figure 2). This includes monitoring and identification methods based on problemsolving approaches. Implementation of real-time fault diagnostics for PV systems as parts of the early warning and identification systems is also explored.

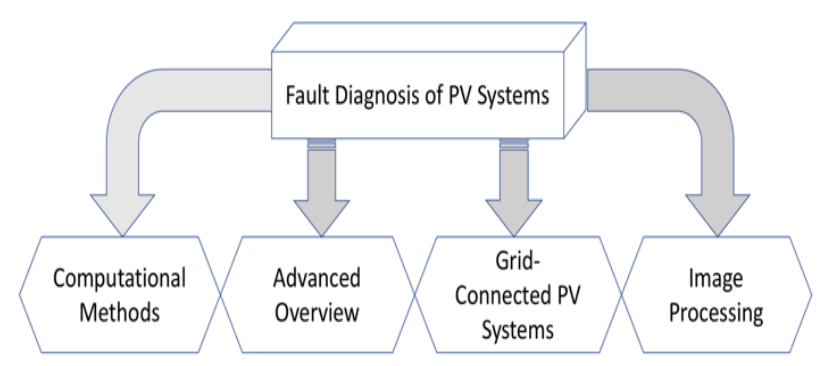

Fig. 2. Structure of fault diagnosis review of PV systems

\section{Computational Methods in Fault Diagnosis of PV systems}

The computational methods found in literature regarding the fault identification and diagnosis of photovoltaic system can be classified into statistical approaches, intelligent methods, hybrid computational methods including soft computing systems and other conventional methods (Figure 3 ). These methods try to solve the non-linearity aspects of PV system faults in order to identify the type of faults and fault locations. A previous paper review has shown that there is considerable uncertainty in the identification of PV system degradation rates. This uncertainty depends on factors such as measurement tools, the data classification and filtering criteria, index measuring performance and statistical approach [14]. Amongst the methods investigated, linear regression method is the most popular but shows the high variation and uncertainty. The autoregressive integrated moving average (ARIMA) method is less popular but it yields low variation and uncertainty. More detailed discussion can be obtained in the following section. 


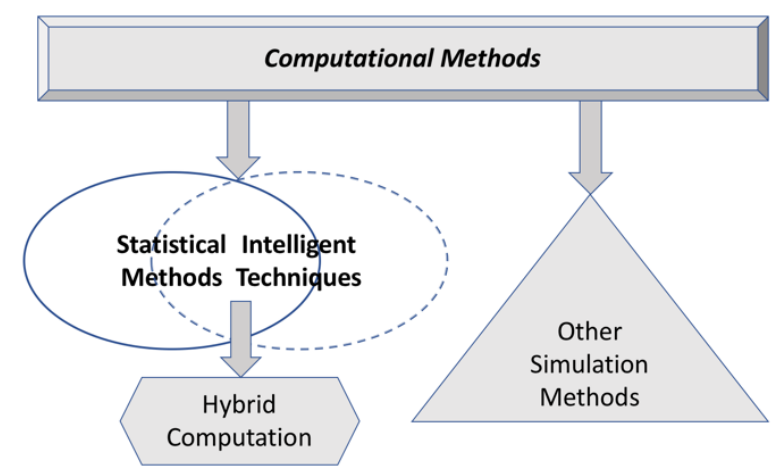

Fig. 3. Computational methods in fault diagnosis

\subsection{Statistical Methods}

Statistical methods have been adapted as the prominent solution for classification and detection of PV system faults (Table 1). The k-nearest neighbours rule has been used in the classification and regression for string connected fault identification and diagnosis of PV systems [15]. This method is comprehensively able to detect and classify different types of faults in real-time, such as open circuit, line to line faults, partial shading with/without bypass diode faults and partial shading with inverted bypass diode faults. In addition, the proposed method accurately traces the performance of PV systems at different insolation and temperature levels. In comparison to this method, shading problems and fault detection on the DC side of a grid connected PV system are investigated with exponentially weighted moving average (EWMA) control chart. The EWMA method was able to identify the parameter changes between the fault and normal conditions [2]. The mechanism is to recognize the normal output parameters of PV system, such as maximum power, current and voltage under different irradiance and cell temperature. The residual, the difference between the measured and predicted output from the single diode model, is taken as the fault indicator of PV systems. Then, a EWMA chart is utilized to monitor the non-correlated residuals to identify the type of fault.

For monitoring performance of PV systems, the statistical approach based univariate and multivariate exponentially weighted moving average (EWMA) charts approach is again utilized to identify and diagnose the faults on DC side of PV system [16]. A deviation number of electrical parameters of PV systems under fault and normal conditions is determined as the fault indicator. In fact, the proposed multivariate EWMA cannot identify the fault types, unless the univariate EWMA scheme is deployed later to identify the short-circuit, open-circuit and shading faults. The monitoring capability of faults in PV systems is improved through the enhanced methods of statistical failure identification [17]. The target of the proposed method is to reduce the false alarm and missed identification rates by deploying the multiscale-weighted generalized likelihood ratio test (MS-WGLRT) method. The reason for this approach is the multiscale nature may provide better robustness to noise and monitoring quality compared to the independently generalized likelihood ratio test method.

Automatic detection and diagnosis of possible faults in grid-connected PV systems based on statistical methods considering climate data and electrical parameters are presented as another alternative [18]. The algorithm of fault detection based statistical t-test is to compare the measured and ideal output power, while the location of fault is determined from the measured and ideal values of DC power to voltage ratio. This method is effectively used to identify different faults in PV panel, PV string and MPPT controller.
Meanwhile, similar statistical methods of t-tests and f-tests are used to investigate the effect of cracks on PV panel electroluminescence measurements [19]. Measurement results indicate that not all types of cracks have significant reduction of output power production of PV panels.

Table 1. Summary of statistical methods

\begin{tabular}{|c|c|c|c|}
\hline Methods & Purposes & Tasks & Refs. \\
\hline $\begin{array}{l}\text { Exponentially } \\
\text { weighted } \\
\text { moving } \\
\text { average } \\
\text { (EWMA) }\end{array}$ & $\begin{array}{l}\text { Early } \\
\text { detection }\end{array}$ & $\begin{array}{l}\text { Shading of PV modules } \\
\text { and faults on the direct } \\
\text { current (DC) side }\end{array}$ & 2 \\
\hline $\begin{array}{l}\text { k-nearest } \\
\text { neighbors rule }\end{array}$ & $\begin{array}{l}\text { Real-time } \\
\text { classification } \\
\& \text { detection }\end{array}$ & $\begin{array}{l}\text { Open circuit, line to line } \\
\text { faults, partial shading } \\
\text { with/without bypass } \\
\text { diode faults and partial } \\
\text { shading with inverted } \\
\text { bypass diode faults }\end{array}$ & 15 \\
\hline $\begin{array}{l}\text { Univariate and } \\
\text { multivariate } \\
\text { EWMA }\end{array}$ & $\begin{array}{l}\text { Detection \& } \\
\text { diagnosis }\end{array}$ & $\begin{array}{l}\text { Monitor the direct } \\
\text { current (DC) side }\end{array}$ & 16 \\
\hline $\begin{array}{l}\text { Multiscale- } \\
\text { weighted } \\
\text { generalized } \\
\text { likelihood ratio } \\
\text { test (MS- } \\
\text { WGLRT) }\end{array}$ & $\begin{array}{l}\text { Monitoring } \\
\& \text { detection }\end{array}$ & $\begin{array}{l}\text { Reduced the false alarm } \\
\text { and missed } \\
\text { identification rates }\end{array}$ & 17 \\
\hline Statistical t-test & $\begin{array}{l}\text { Automatic } \\
\text { detection \& } \\
\text { diagnosis }\end{array}$ & $\begin{array}{l}\text { Faults in grid connected } \\
\text { PV systems }\end{array}$ & 18 \\
\hline $\begin{array}{l}\text { Statistical t-test } \\
\& \text { f-test }\end{array}$ & Identification & $\begin{array}{l}\text { Effects of crack on PV } \\
\text { cells }\end{array}$ & 19 \\
\hline
\end{tabular}

\subsection{Intelligent Techniques}

Intelligent techniques are the most popular methods for solving any engineering problems nowadays, including the problems of identification and fault diagnosis in PV systems. The noticeable advantages of these methods include symbolic reasoning, flexibility, and the ability to explain results. They are also able to analyze and identify non-linear, large, complex and even incomplete data patterns. Compared with standard linear models for optimization methods, intelligent computational methods have compact solutions for multivariable problems without requiring knowledge of internal system parameters. For these methods, only a training process is required to directly determine the output parameters. These solutions are obtained without solving any non-linear mathematical equations or making statistical assumptions as in the conventional optimization methods. A summary of intelligent methods application is provided in Table 2.

Amongst the methods, the artificial neural network (ANN) is the most fundamental model used to detect and classify faults occurring in PV systems [20]. The method has been used for detecting partial shading faults in PV systems under different input scenarios [21]. Both studies are actually comparing the output current, voltage and maximum power point between the ideal model and output estimation from neural network. The use of ANNs is also recognized for monitoring and diagnosing of real-time PV plant management. An ANN knowledge-based diagnosis system has capabilities to estimate the key components that can aid in damage prevention, extend critical components life-time, improve overall system performance and reliability, minimize off-line analysis effort and maintenance costs, and allow remote plant monitoring, diagnosis and evaluation [22].

Intelligent technique based machine learning methods have been approached for fault detection and diagnosis. This could be the prominent solution for fault detection in PV systems. An example would be using a decision tree 
algorithm applied to grid connected PV systems [23]. A learning method based non-parametric model is used to predict the performance of PV systems, while a data set under different climate conditions is collected through acquisition system. The target of this study is to estimate whether the state of PV system is in either normal or faulty conditions. The faulty conditions are classified as string, short circuit or lineline faults. The testing results indicate the high prediction performance and accurate diagnosis that imply the robustness, effectiveness and efficiency of proposed method.

Identifying a fault condition in PV systems is quite tricky because the non-linear characteristic of the system outputs is highly susceptible to climate conditions. For PV system diagnostics, common potential problems exist regarding the performance, modelling and sampling of experimental data. The performance is sometimes not satisfied due to the lack of monitored fault information. The appropriate model is not reached due to less efficient data collection for model training. Also, it is quite difficult to obtain the fault data samples from field experiments. Therefore, the new approach of fault detection based machine learning methods is introduced using a vector of seven dimensions based on the I-V parameters response to environmental conditions. This vector is proposed as the input to the fault diagnosis model, using the emerging kernel based extreme learning machine (KELM). KELM is characterized as having extremely fast learning speed and good generalization performance. The NelderMead Simplex (NMS) optimization method is utilized to optimize the KELM parameters which influence the classification performance [24]. Through simulation and experimental results, the optimized KELM approach for fault diagnosis of PV systems is highly accurate, reliable with improved generalization performance.

With high efficiency being the main target of PV system development nowadays, there is a trend to increase in PV plant capacity. The provision method for PV fault identification is an important tool in the effort to increase the PV system efficiency. In this case, the meta-heuristic optimization techniques, such as Genetic Algorithm (GA), Tabu Search (TS) algorithm and Grey Wolf Optimization (GWO) are utilized as the fault diagnostic tools to detect and classify the open circuit and short-circuit faults under nonuniform distribution of sunlight intensity and temperature [25]. These methods have achieved successful identification and localization of fault types under different testing scenarios. The Improved Real Coded Genetic Algorithm (IRCGA) is another meta-heuristic optimization approach that can be used to detect, localize and distinguish the open and short-circuit faults under non-uniform sunlight intensity and temperature distribution [26]. After extensive simulation performance, the IRCGA method accurately estimated the possible fault location and type of faults. Providing efficient and effective fault diagnosis methods is necessary to ensure the continuous power production in PV systems.

A wavelet modification method called wavelet packet transform (WPT) can be used to detect the different types of faults in grid connected PV systems [27]. The research results show that the performance of the WPT method is better than the conventional wavelet transform in detecting faults from normal operation conditions under different testing scenarios measured by the energy output and standard deviation performance index. In comparison, the wavelet transform method in [28] uses an approach to avoid several problems in conventional fault detection systems. This method reduces the need for additional hardware and sensors that impacts the cost. The method is also less dependent on changes in inverter specifications. The diagnostic function design of this multilevel decomposition wavelet method is based upon the normalized standard deviation of the wavelet coefficients. It is shown to be highly efficient and accurate in detecting the fault location including in the inverter. In addition, the proposed method is verified through simulation and experimental results.

Table 2. Summary of intelligent computational methods

\begin{tabular}{|c|c|c|c|}
\hline Methods & Purposes & Tasks & Refs. \\
\hline $\begin{array}{l}\text { Artificial } \\
\text { Neural } \\
\text { Network } \\
\text { Decision tree } \\
\text { algorithm }\end{array}$ & $\begin{array}{l}\text { Detection \& } \\
\text { diagnosis }\end{array}$ & $\begin{array}{l}\text { Faults in general } \\
\text { Partial shading patterns } \\
\text { Faults in grid connected } \\
\text { PV systems }\end{array}$ & $\begin{array}{l}20 \\
21 \\
23\end{array}$ \\
\hline $\begin{array}{l}\text { Optimized } \\
\text { kernel based } \\
\text { extreme } \\
\text { learning } \\
\text { machine } \\
\text { (KELM) }\end{array}$ & Diagnosis & $\begin{array}{l}\text { Improvement model in } \\
\text { fault studies }\end{array}$ & 24 \\
\hline $\begin{array}{l}\text { Meta-heuristic } \\
\text { optimization }\end{array}$ & $\begin{array}{l}\text { Diagnosis \& } \\
\text { identification }\end{array}$ & $\begin{array}{l}\text { Location and types of } \\
\text { open-circuit and short- } \\
\text { circuit (SC) faults }\end{array}$ & 25 \\
\hline $\begin{array}{l}\text { Improved Real } \\
\text { Coded Genetic } \\
\text { Algorithm }\end{array}$ & $\begin{array}{l}\text { Diagnosis } \\
\text { strategy }\end{array}$ & $\begin{array}{l}\text { Location and types of } \\
\text { open-circuit and short- } \\
\text { circuit (SC) faults }\end{array}$ & 26 \\
\hline $\begin{array}{l}\text { Wavelet } \\
\text { transform }\end{array}$ & $\begin{array}{l}\text { Detection \& } \\
\text { identification } \\
\text { Detection } \\
\text { algorithm }\end{array}$ & $\begin{array}{l}\text { Normal and fault } \\
\text { conditions } \\
\text { Fault locations and } \\
\text { inverter components }\end{array}$ & $\begin{array}{l}27 \\
28\end{array}$ \\
\hline
\end{tabular}

\subsection{Hybrid Computational Techniques}

No single computational technique has been found to be superior to others in all conditions. Therefore, hybrid computational paradigms are currently trending as proposed methods for solving real engineering problems including PV system fault diagnostics. In this respect, the strengths of the hybrid components are taken while eliminating the weaknesses of individual components. The hybrid computational techniques in this case could be the combination of a statistical approach and intelligent techniques or a conventional method and intelligent techniques (Table 3).

For instance, the Adaptive Neuro-fuzzy Inference System (ANFIS) is actually the hybrid paradigm between the artificial neural network and fuzzy logic systems. If the systems get more complex and non-linear, the implementation of fuzzy logic is more difficult and requires extra computational time to determine the appropriate fuzzy rules and proper membership functions. In addition, although the fuzzy logic system has the reasoning capability, it has no ability to learn and to adapt. Meanwhile, the conventional artificial neural network needs extra computational efforts and is less effective and more complicated when the data structure gets more complex and the number of data patterns increases. Nevertheless, the artificial neural network has the ability to learn and adapt to the variations in input-output data. Therefore, the ANFIS network provides the benefits of both methods to end up with the one powerful method for the prediction, estimation and control of dynamic and complex systems in engineering problems. Related to this method, the Multiclass Adaptive Neuro-Fuzzy Classifier (MC-NFC) is used for fault detection and classification [29]. In this case, the Adaptive Neuro-fuzzy Inference System (ANFIS) is developed to improve the performance of automatic fault classifier based fuzzy logic. The proposed method has better accuracy compared to the Artificial Neural Networks (ANN) classifier in terms of fault classification tasks. 
The hybrid learning algorithm called extension neural network, which combines the extension distance from extension theory and neural network process, is applied to detect the islanding condition in PV systems [30]. In this case, the neural network process includes learning, recalling, generalization and parallel computing characteristics of a neural network (NN). The proposed method is able to correctly identify different fault signals during intentional or inadvertent islanding conditions.

In other cases, the neuro-fuzzy approach is used to calculate sets of parameters under different measurement scenarios [31]. In this study, the status operation of PV system is determined by the evaluation and comparison of norms based on sets of parameters. The method is able to use a threshold value to distinguish between the normal and faulty conditions in the existence of noise and disturbances.

Another hybrid combination between neural network and fuzzy logic system is proposed for fault identification based upon radial basis function neural networks and fuzzy logic systems that use both Mamdani-Sugeno fuzzy types [32]. The simulation results indicate that the proposed method accurately to detects and locates different types of faults, for instance faults in PV module, two faulty PV modules and partial shading faults. Different artificial neural networks are tested in order to obtain the high accuracy performance, while the performance both type of fuzzy systems is similar. The only difference in different fuzzy system implementations is the representation of rules and output membership function for fault detection. In another study diagnostic parameters and fuzzy logic rules are developed based on system currentvoltage characteristics. These were used to detect different fault types, such as shading problems, losses in series resistance and degradation potentials [33]. The advantages of fuzzy logic are no required accurate description of the system to be controlled and no need to compensate for wide parameter variations which is unlike the standard regulators. In this respect, an algorithm that combines a third-order polynomial function and classifier fuzzy logic system may increase the PV system fault detection accuracy. It has been shown that such a system could be developed using parameters of voltage and power ratios during faults. The detection limits for these parameters are classified with the fuzzy logic method [34], [35].

Nowadays, smart monitoring and modern data acquisition can be readily implemented due to the availability of advanced devices, such as such as sensor networks, smart combiner boxes and smart inverters. Thus a monitoring system based pre-filter Elman Neural Network and decisionmaking rules are introduced as the identification and classification methods for open-circuit and partial shading faults [36]. Both the pre-filtering technique on time series input and the modification decision making increase the fault detection capability of PV systems. In addition, the utilization of the improved radial basis function (RBF) kernel extreme learning machine (ELM) optimized by simulated annealing algorithm is proposed for fault detection [37]. In this case, the simulated annealing method is carried out to optimize the RBF-ELM model. The simulation results show that the proposed method can be fast and accurate in detecting different types of faults, such as short circuit, aging material and partial shading.

Accurate monitoring of parameters in grid-connected PV systems, such as grid voltage and frequency, voltage and current of the AC and DC converters, as well as climate data such as temperature and irradiance, influences the reliability of energy supply. A monitoring method that combines statistics, optimization and identification techniques based upon Exponentially Weighted Moving Average (EWMA), multi-objective optimization (MOO) and wavelet representation, respectively is developed using Wavelet Optimized EWMA (WOEWMA) [38]. The target of this method is to minimize the missed detection and false alarm rates which are determined by the MOO method. Although the developed monitoring technique is quite complex, the proposed method is able to identify both single and multiple faults including bypass diode, mismatching losses and shading faults.

For faults occurring in the grid connected PV systems, a new parallel algorithm is introduced to detect the faults on the DC and AC sides utilizing data measurements evaluated with t-statistical analysis methods [39]. Different scenarios are deployed and simulated using virtual instruments-based LabVIEW software. These scenarios include variation in operational status, sunlight intensity and cell temperature as well as a variety of voltage and power ratios for a PV string connection. More complete types of faults can be detected using this method, for instance faults on PV panel, string connection, bypass diode, MPPT controller and power $\mathrm{DC} / \mathrm{AC}$ converter.

Table 3. Summary of hybrid computational methods

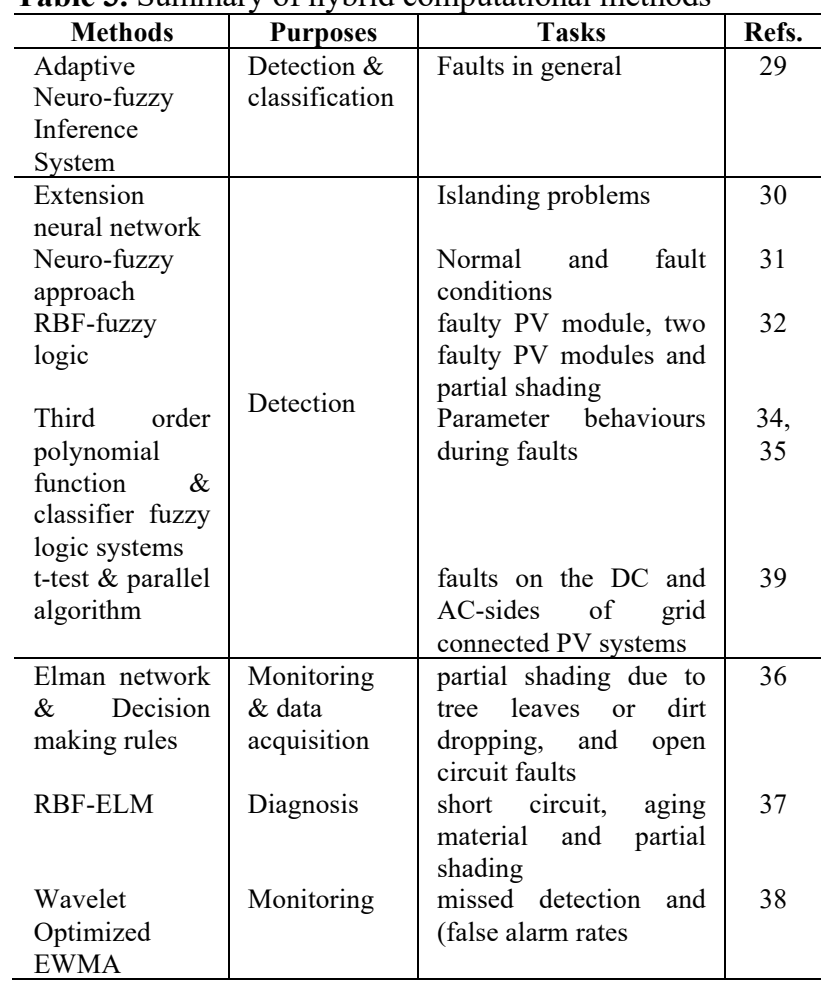

\subsection{Other Simulation Methods}

The mismatch of different I-V characteristics lead to significant power loss of PV systems. These losses are shown to depend on the maximum power point voltage, current and cell fill factor in critical level [40]. The early detection of PV system degradation and failure modes is highly important to increase the system reliability. The degradation of long term electrical performance and failure modes such as cracked and deformed cells are investigated through the I-V curve estimation. This investigation was done under unpredictable weather conditions in a desert area [41]. In other cases, the electric and thermal characteristics of PV module are investigated during partial shading condition and bypass diode damages [42]. The behaviour of PV systems under fault conditions is evaluated through the I-V curve methods from 
the ideal model and empirical data. The obtained results show that the open circuit voltage of damaged bypass diode is a little higher than the when partial shading occurs. Meanwhile, the temperature of the junction box due to shading problems is higher than when bypass diode damage occurs. However, when the PV module is not operational because of bypass diode damages, extremely high temperatures might be observed in the PV module junction box.

The local outlier factor (LOF) method is utilized to identify fault conditions by comparing the parameters between fault and normal conditions. A conventional LOF method can properly identify underperforming strings using PV string current since that current is characterized as nonstationary stochastic. However, the LOF value changes with the value of PV string current. Therefore, the method is not suitable to determine the degree of fault which consequently influences the accuracy of the fault evaluation. In this case, a modified LOF algorithm is introduced and claimed to have better performance than the conventional one. The improved performance was verified based upon several simulations and testing on a real PV system [43]. A time series sliding window of photovoltaic string current can also be utilized to identify fault types and locations [44]. In this case the LOF of the localized strings is continuously calculated. A fault is determined when the LOF of a string exceeds at threshold value. This method is claimed to accurately detect open circuit, short circuit and shading fault conditions.

The study to increase PV system efficiency under nonuniform insolation and partial shading fault is proliferating [45]. In this case, the behaviour of PV system during normal and faulty conditions is analysed and optimization methods employed to approach the real performance of PV systems. The performance of PV systems under different partial shading scenarios and faulty condition is investigated with different array connections and measurement parameters [46] The effects of shading problems of string PV systems have been simulated, validated and analysed with Ltspice IV software [47].

Table 4. Other simulation methods in fault diagnosis

\begin{tabular}{l|l|l|c}
\hline \multicolumn{1}{c|}{ Methods } & \multicolumn{1}{|c|}{ Purposes } & \multicolumn{1}{c}{ Tasks } & Refs. \\
\hline I-V curve & $\begin{array}{l}\text { Early } \\
\text { identification }\end{array}$ & $\begin{array}{l}\text { Cracked cells and } \\
\text { physical material } \\
\text { defects } \\
\text { Partial shading or with a } \\
\text { damaged bypass diode } \\
\text { Partial shading and hot } \\
\text { spot problems }\end{array}$ & 42 \\
\hline Detection & $\begin{array}{l}\text { Detection \& } \\
\text { evaluation } \\
\text { Detection }\end{array}$ & $\begin{array}{l}\text { Degrees of fault and } \\
\text { location } \\
\text { Open circuit, short } \\
\text { circuit and shading fault } \\
\text { conditions }\end{array}$ & 43 \\
\hline $\begin{array}{l}\text { Ltspice } \\
\text { Software }\end{array}$ & $\begin{array}{l}\text { Simulation of } \\
\text { I-V curve } \\
\text { reduction }\end{array}$ & $\begin{array}{l}\text { Fffects of Partial } \\
\text { fault } \\
\text { identification } \\
\text { Circuit and short-circuit } \\
\text { faults including the } \\
\text { partial shading condition }\end{array}$ & 47 \\
$\begin{array}{l}\text { Extension } \\
\text { diagnosis }\end{array}$ & $\begin{array}{l}\text { Modelling \& } \\
\text { simulation }\end{array}$ & \begin{tabular}{l} 
Fault types and analysis \\
\hline
\end{tabular} & 52 \\
\hline
\end{tabular}

The performance between no-fault and fault conditions of PV system is defined based on the estimated energy losses [48]. The type of faults in this case are long and short term zero efficiency faults, shading problems and non-zero efficiency with non-shading faults. The output power performance of PV system is investigated during the shading problems and inverter faults [49]. In this case, when operating in MPP mode the maximum power under shading and non- uniform insolation conditions is lower than the normal condition. This power difference can be used as a fault indicator. However, when the load is reduced the voltage ratio can be used instead. Meanwhile the inverter faults can be monitored using an output power profile. For a switch stuck open the output power will be zero. For a switch stuck on the output power will have a sinusoidal wave appearance. Shading problems on PV systems produce high impact on the power production but also create hot-spots that may lead to reduced PV performance and lifetime. One method of providing credible shading identification is by the comparison of I-V curves during the normal and shading conditions measured. The derivative of this error over voltage can determine if one or more cells are dissipating power [6].

Moreover, studies to improve the efficiency of PV system during non-uniform irradiance and fault conditions are gaining much attention. One method to distinguish opencircuit and short-circuit faults, including the partial shading conditions, is introduced based on the operating string voltage and temperature [50]. This approach is taken to reduce the number of sensors and thereby reduce the cost of the monitoring system. An open-circuit and short-circuit identification method using reduced sensors can be simply presented for the cases of string connected PV systems [51]. Only three sensors are needed, i.e. the pyranometer, temperature and DC power meter, in the proposed fault diagnostic systems.

Table 4 summarizes the other modelling simulation methods in fault diagnosis of PV systems. Modelling and simulation of PV systems is important factor to understand the behaviour of system under normal and fault conditions. Variations in electrical parameters associates with changes in climate conditions can be observed from the simulation results. These data are then processed with standard algorithms such as the extended correlation function and the matter-element model [52]. This method is called the extension diagnosis method and can identify a PV system fault accurately. Also, a PV system fault detection method is implemented using parameter modelling of electrical characteristics and the energy balance equation [53]. To obtain these parameters, some factors such as total effective solar energy, total heat exchange coefficient and ambient temperature are calculated based on the temperature monitored in a thermal camera. Variations in data monitoring results might indicate if the PV system is either experiencing a fault or operating under normal conditions.

\section{Advanced Overview of Fault Diagnosis in PV Systems}

The research of PV systems is proliferating in conjunction with their increase in complexity. The reliability of gridconnected PV systems with regards to their normal and safe operation is one of the main considerations for their development. Reliability, maintenance and operational costs are always major concerns to increasing the percentage of PV systems connected to the grid. Provisions for early and highly accurate identification and diagnostic methods of faults in PV systems, such as shading problems, cells material degradation and supporting components faults, may prevent extensive maintenance and power losses thus minimizing the costs. Early and accurately warning systems for fault detection and diagnosis are very important in this respect to avoid the potential damage of PV plants due to the risk of fire and to increase the system efficiency and reliability [1]. Again, the fault detection is essential to maintain the reliability, 
productivity, safety and efficiency [2]. Therefore, it is important to have fault detection techniques with fast response and high accuracy to avoid the risky problems related to overall PV system installations. In this case, the advanced overview of fault diagnosis of PV systems including the real-time monitoring, fault tolerant control and low voltage ride through (LVRT) and protection system performance is shown in Figure 4.

\section{Advanced Overview of Fault Diagnosis}

\section{Real-Time Monitoring}

\section{Fault Tolerant Control and LVRT}

\section{Protection Systems}

Fig. 4. Advanced overview of fault diagnosis

\subsection{Real-Time monitoring and fault diagnosis of PV systems}

PV systems are characterized with non-linear and unpredictable energy output performance according to environmental factors. In addition, because the installation PV system is located in open-space and exposed environments, it is necessary to accurately monitor the system in order to ensure reliable system performance. Reliability enhancement and maintenance reduction are key points needed to gain the benefits of competitive grid connected PV system because the feeding energy means income of the PV owners. For these reasons, the existence of a fault is intolerable; therefore, providing online monitoring systems would be beneficial for developing high efficiency and maximizing available output energy. In this case, the nonuniformity index based DC and AC output power is proposed to monitor performance for both normal and faulty conditions of PV systems [54]. This method allows in reducing the number of sensors and applies to any dimension of PV plants. Also, the method effectively estimates the PV system efficiency validated by performance ratio and corrected performance ratio indicators.

A monitoring system is an important tool in maintaining the optimal operation of PV systems. In this respect, automatic fault detection is supposed to be available in realtime to avoid a power and energy disconnection due to proceeding faults. In this case, a fault location detection method is introduced utilizing the difference between the terminal voltage of a faulty string and a non-faulty string in PV modules [55]. The approach is claimed to able to reduce the number of string current and non-optimal voltage sensors in a PV system. One advantage of this research is the use of power line communications for transmitting the data used to monitor the PV panel performance. A user friendly web application for monitoring the performance was also designed to allow internet access. In addition, an economic analysis is provided to measure the cost-effective of fault diagnosis tools in PV systems.

Early monitoring and detection methods for remote failures of PV systems are presented to reduce potential of energy losses that might go undetected for a long time. In this case, the automatic detection continues to process a routine check in order to inform the operators about the most probable fault types and location. PV system monitoring is also prominently designed to improve the system performance and provide potential failure information in order to improve system reliability. A wide range of monitoring strategies can be implemented based on output power profiles. Such profiles can be used to the control location based power converters and communication devices [57]. In this case, the highly sophisticated PV systems should be considered in order to have better monitoring for different types of PV system failures. In other perspectives, online monitoring of PV system degradation is presented by progressive alteration of a single diode model equivalent circuit including the series and shunt resistances [58]. The difference between the modified and original model components are measured and recorded. This approach is identified as being very accurate procedures without needing extra sensors or changing the operating point.

The real-time monitoring and fault diagnosis of PV systems is presented that compares the performance of faulty PV panel to an ideal model [59]. A fault signature is determined from the shape changes of I-V curve under normal and fault conditions. Then, the fault threshold is determined by the Euclidean norm between these two conditions. From the measurement, the value of the min-max deviation range is correlated with the fault types, such as wiring faults and shading problems. Nevertheless, it seems that the term of realtime monitoring fault diagnosis systems is not clearly presented in this research since there is no description of how to deploy the fault threshold into the connection tools for realtime systems. It is totally different with the following research where a real-time fault diagnostic meter for PV systems is developed based on extension theory [60]. In this method, parameters of PV systems during normal and fault condition are obtained by Solar Pro software package. These collected data are used to design a matter-element model for the PV system. This model combined with a PV system program are deployed in a PIC microcontroller. This method is claimed to be simple due to the small amount of required data for model construction and lack of any learning procedure. Results indicate a high accuracy in fault diagnosis. Since a PV system installation is outdoors in a remote location, a wireless sensor technology is utilized to connect the PV system to the microcontroller for the real-time monitoring and fault diagnostic systems.

The communication system is one of the vital components in the real-time monitoring of PV system performance. The real-time monitoring and smart metering systems are designed to measure the performance of string PV inverters. They are implemented using a microcontroller unit which uses signal processing techniques on the data before transmitting the serial communications [61]. In other cases, online monitoring of a PV system is effectively and economically proposed based on an open-source platform [62]. This system includes a data acquisition system, transmission hardware, a data gateway, and an on-line monitoring center. For fault identification, the Support Vector Machine Firefly Algorithm (SVM-FFA) is installed in the gateway. Through this approach, a large amount of data can be visualized and PV fault detection can be performed with great accuracy. The automatic supervision and remote fault 
detection based open platform communication (OPC) for monitoring system is another method for communicating PV system data [63]. The approach takes the advantages of standard OPC schemes. For example, data acquisition from devices that have different communication protocols are able to be connected together universally in PV system environments. In this respect, the OPC standard supports collaborative software objects in distributed non-uniform environments. Thus supervision and diagnosis of isolated systems can be combined for the evaluation performance of grid connected PV installations.

An additional method of fault detection in PV systems is designed with the use of distributed MPPT controllers and power optimizing converters and inverters [64]. The diagnostic tools are reported to identify fixed object shading, dirt problems, hot-spots potentials, reduced module performance and excessive losses in cable connections. Also, the users may receive early warning about potential faults through the power losses alert. The benefit of this proposed method is the need for less sensors thus reducing the installation cost. Similarly, an alternative method for PV system automatic fault monitoring and detection is proposed based upon power loss analysis and current/voltage ratios [65]. In this case, the real-time data measurements are used to calculate capture losses indexes. These indexes would act as fault signal indicators for the developed fault monitoring systems.

The misdetection of PV system performance may occur due to the under-performing monitoring systems. Therefore, anomaly detection is important to allow the correct predictive maintenance procedures. An anomaly detection algorithm is introduced taking advantage of an artificial neural network method to estimate the AC power production using solar irradiation and PV panel temperature measurement [66]. The model estimation results are compared with the online data from PV systems to obtain the residual parameters which can act as an alert to undesirable PV system performance. In addition, the residual parameter can be used to develop an anomaly index that would indicate to operators when predictive maintenance should be done to avoid potential faults.

\subsection{Fault-Tolerant Control and Low Voltage Ride- Through}

Methods of fault detection and isolation are proposed based on the optimum maximum power point tracking (MPPT) controller performance under abnormal operating condition to improve upon typical MPPT algorithms that ignore the fault conditions during the tracking process. This method is called the fault-tolerant control (FTC) strategy which tries to localize and monitor suddenly changes in the PV system performance and re-adjust the MPPT controller to find the new best operating maximum power point [67]. In this case, the reconfiguration of MPPT algorithm is based on the hybrid combination of incremental conductance and modified current based particle swarm optimization techniques. The simulation results show this method was successful in detecting different types of faults. In addition, the fault tolerance of different PV array configurations is investigated regarding the solar cell characteristic and shading problems [68]. In this study, it was observed that the bridge link PV array connection is better than two other connection types, total cross tied and series parallel. The bridge link was found to be more fault tolerant under non-uniform irradiance conditions.
The low voltage ride-through (LVRT) grid connection standard for PV systems is a necessary consideration when maintaining a PV connection during faults. For this reason, a LVRT control strategy is designed for grid connected PV system when balanced and unbalanced grid faults occur [69]. In this case, the control strategy to maintain the reliable performance of PV systems under grid faults covers several aspects. These include calculation of the power references following grid codes, a method of reducing active power that is suitable for maintaining dc-link voltage, limiting peak current to prevent inverter overcurrent and reference calculation for three current reference generators. The issues of fault ride through of PV systems under grid faults are commonly discussed since the PV system capacity is increasing in low voltage distribution networks [70]. The successful control strategy for fault ride through of PV units can be achieved through appropriate design and control of the inverters connected to the distribution network. To design such improved fault-ride through control, an energy storage system is required and the optimum value of interface reactance should be determined. Different PV capacity and system load scenarios need to be considered when determining the interface reactance.

With a conventional rotating machine in a fault condition, the overcurrent relay (OCR) may operate perfectly due to the high magnitude fault current from the machine. This condition will not be found in the PV systems due to the current constraints in the inverter components. However, an accurate overcurrent relay setting is also necessary in PV system. Therefore, much discussion is focused on understanding the current characteristics of inverter units due to fault conditions [71]. It is expected that proper performance of overcurrent relays can be obtained from inverter fault currents by using control strategies related to the grid requirements for low voltage ride through (LVRT) with reactive current injection (RCI).

\subsection{Performance of Protection Systems}

The degradation of PV system performance clearly reduces power production. Along with that, consideration of how the PV system degradation affects the protection system is highly important to ensure the safety and reliability of a PV plant. The relationship between PV performance degradation and PV fault conditions is investigated through different short circuit fault conditions [72]. Several methodologies have been investigated to measure the degradation rate. and it was shown that the calculated degradation rate is highly dependent on the method used as well as the as the technology and site [14]. The results indicate an increase in degradation leads to a reduction in string fault current. Such a reduced current might be undetected with conventional protective devices.

In terms of safety consideration, a PV system in a grid connection is quite unique due to the existence of $\mathrm{DC}$ power. Therefore, the potential fire risks in the PV plant connection are high if a fault is undetected [73]. It is very important that the selection of protective devices and grounding systems be properly assessed in order to avoid fire risk. Also, it is recommended to cross-check all potential failure during system design and to do an early assessment of potential fire hazards in the system. In addition, protection challenges due to the increased penetration of PV systems in distribution systems are investigated [74]. A PV system is connected to the grid network through an inverter. With an inverter the active and reactive power as well as the limit and sequences of fault current contributions can be controlled. In this case, relay coordination and protection reliability improvement can 
be achieved by using zero and negative sequence currents with conventional overcurrent relay protection systems.

Protection systems are always challenging with the increase power capacity of PV plants. Although protection standards have been implemented in many cases PV system faults can remain undetected. In fact, a reliable method of fault identification is highly required to ensure the reliability performance of PV systems. In this respect, the review and analysis of PV system protection and fault diagnosis is very important to address undetected fault conditions including along with the impact of such faults [75]. The challenges in developing protection systems include sensor requirements, capability to diagnose and localize faults, integration complexity, accuracy and incremental costs. Improvement of protection system performance in the case where a large capacity of PV plants is connected to the grid with an inverter interface can be considered under several different scenarios. These scenarios include PV output fluctuation, different location of faults in the network and system load [76]. In this case, the investigated parameters are current variation within a short time window and the positive sequence fault component. Using these parameters an improved reverse power protection can be developed that includes protection logic.

The detection and isolation of a DC arc fault in PV systems is quite challenging because there are no zero current crossing points. This type of fault may influence to the stability of PV systems if there are no suitable protection systems. The reference [5] has provided comprehensive studies of methods, characteristics and fault diagnosis regarding the DC arc fault detection in PV systems. The DC arc fault in PV system can be detected by the parallel capacitor current utilizing time and frequency characteristics [77]. In this method, a capacitor is connected parallel with the load. Then series arc faults are generated in different location of series and parallel PV panel systems. When a series arc exists, the DC bus capacitor will pass the high frequency current components. In this case, the polarity and amplitude of the capacitor currents integrated with the frequency spectrum of the current are analyzed to distinguish the different types of DC arc faults from other abnormal conditions. This method requires the collection of a large amount of off-line data for the online monitoring of a DC arc fault in PV systems.

The contribution of fault current from PV systems in a distribution network has been extensively discussed [78]. In spite of the non-linear and uncertain characteristic PV systems, the proposed method is expected to accurately locate faults without the need for dynamic PV system models. In a similar study [79], the coordination of protective relays is the main concern when the PV system fault current contribution increases in a building distribution network. Simulation results show that the magnitude of fault current is not only depending on the size of PV plants but some other factors. Therefore, the review of protection settings and relay coordination are required before connecting PV system to a distribution network.

Having a significant PV system capacity on the grid may change the fault current profile and of course give threaten the protection system performances. To overcome such condition, the three-phase fault current contribution from a PV system connected to a voltage source inverter is modelled. The proposed model that covers the environmental input of PV system, current limit of inverter and effects of reactive power from the inverter control system can be integrated into a conventional balanced short circuit study [80]. The main target of this study is to investigate the impact of a PV system output on the breaking capacity of the interrupting protective devices during grid faults. A significant capacity of PV systems influences the performance of the grid protective systems [81]. Also, their output characteristics requires different considerations when compared to short circuit current behaviour of conventional generation systems. Considerations need to be made terms of symmetrical or unsymmetrical short circuits components. The contribution to the grid fault current depends on the control strategy and algorithm applied in the grid interfaced inverter. Therefore, this problem has to be taken into account by the planning operator during grid expansion. Special consideration is needed for designing the proper setting of protective devices and network security functions.

The installation PV system is usually in an open space roof top location. Therefore, a lightning strike is the most threatening factor for the owners because it is correlated with the facility safety and output power reliability. In this case, a lightning protection system is very important for a PV system installation for the sake of fault clearance, equipment fire hazards and other dangerous effects [82]. For these requirements, it is essential to have practical guidelines and standards for PV system protection to lightning strike threats. A fire hazard in rooftop building integrated PV systems has occurred because of undetected ground faults found in fusebased protection systems [11]. For this reason, a numerical simulation and analytical approach are carried out to investigate the limited utilization of fuse-based ground fault protection. The results of this investigation can be used to identify the proper setting of protective devices in PV systems. To ensure the simulations are correct, the results were validated through experimental measurements. Such results could be used to set thresholding of residual current detector, current sense monitor, and isolation monitor devices. In this case, the proper setting of protective devices can be achieved using the historical data in order to prevent unwanted device tripping and to improve fault detection capabilities.

The performance of an overcurrent relay (OCR) is investigated there are large current variation resulting from fluctuations and short-time dynamic changes of sunlight intensity as well as sudden connection and disconnection of PV system feeders [83]. The control strategy is simulated through PSCAD software considering PV systems with inverter/converter units and a filter. These simulations include systems with and without battery storage. Power congestion is a main consideration of this method. The optimum OCR performance is investigated with a particle swarm optimization (PSO) algorithm to determine the prominent setting of relay protection under $\mathrm{PV}$ power fluctuations.

Considering another computational method, a fault analysis for multiple PV grid connected inverters in a distribution network is performed with the Inverter Matrix Impedance Current Vector (IMICV) method. This method uses symmetrical components in combination with the Inverter Matrix Impedance and the Impedance-Current Vector [84]. The method is utilized to solve a linear system of equations after a fault to find the current in the substation, voltages at the fault point and voltages at the PV gridconnected nodes. Computational and simulation results indicate the proposed method is efficient and accurate without requiring complex programming.

\section{Fault Diagnosis on Grid-Connected PV Systems}


A system is defined as complex combination of components and sub-components, where technical and non-technical disciplines mutually interact. In this case, an inductive and conservative system reliability analysis method called failure mode effect analysis is introduced for PV systems [85]. Each component/sub-component is independently analysed to identify the potential failures which may affect other components or the overall system. In a related study, the automatic supervision, fault identification and diagnosis of potential failure points in a grid connected PV system are presented. This method is based on comparison of simulation and measured results as well as deviations in DC current and voltage [86]. In this case, the monitoring system at the same time performs modelling and simulation of the complete system and includes the measured parameters in real-time. An example automatic fault detection in grid-connected PV systems is shown in Figure 5.

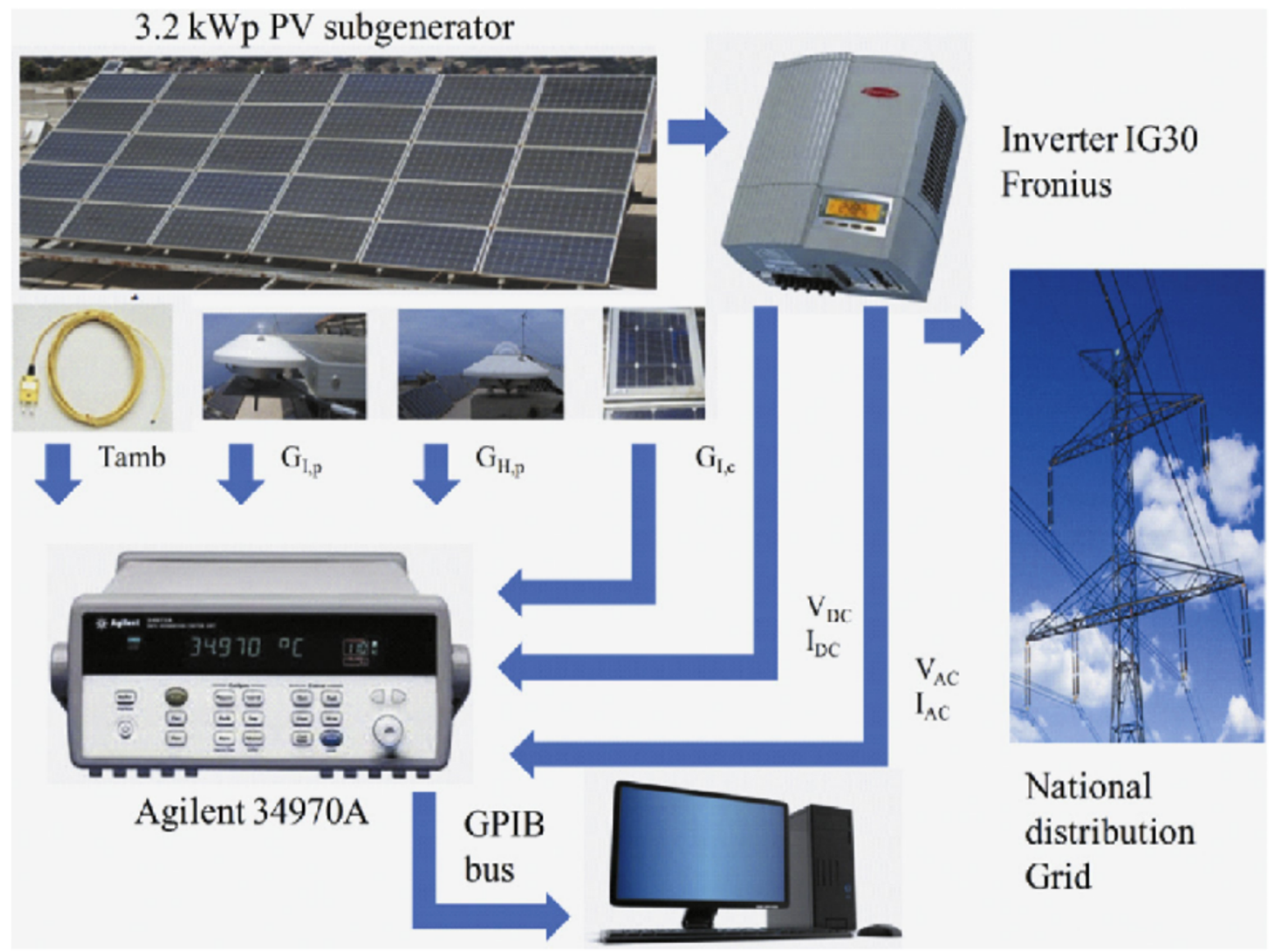

Fig. 5. Schematic diagram of automatic fault detection [86]

Automatic fault identification and diagnosis of grid connected PV systems have gained attention as prominent issues since the capacity of PV implementations have become significant [87]. In this case, supervision and diagnosis of PV system performance are reviewed, and control strategies for automatic detection are discussed according to the availability of different algorithms and monitoring data. The reliability performance is important to be addressed when the PV system is continuously supplying power to the grid. In this respect, the potential degradation of grid-connected PV systems has been investigated to uses an index to assess system installations [88]. A method of fault detection and diagnosis for both off-grid and on-grid connections of PV systems is presented with claims it is capability of detecting the type and location of faults [89]. In this case, the proposed model depends on the PV site measurement and a prediction output model for fault identification. For this reason, several types of sensors are employed to monitor the input parameters and PV system performance. This system also uses power line communications for the monitoring systems. A simple computational algorithm is developed to display each 10 minutes of important information regarding PV module performance and to send this information to website for the internet access monitoring. The basis of this proposed method is a of microcontroller that functions for both data communication and fault detection without any additional hardware and simulation software.

The automatic fault identification for fault location of grid connected PV systems is proposed monitoring the ratio of DC over AC power [90]. Diagnostic signals, displayed 10 minutes on a monitoring device, are correlated to different fault locations. Monitored conditions include PV module faults, PV string faults, inverter, faults due to partial shading, PV ageing and MPPT malfunction. The proposed method has been tested on a real PV system installation accurately diagnosing faults in different location for both DC and AC sides of PV plants. Similarly, the automatic fault detection of grid connection PV systems is proposed by the evaluating a current and voltage index [91]. A threshold for this index is determined to investigate the fault and normal conditions in different array PV configurations. The method highly reduces the cost of sensors and can be adapted for use with inverters without additional external hardware and software.

Large capacity PV systems consist of very complex wiring connection making it will very difficult to identify the fault location within this complex structure. Most previous fault identification techniques have failed to address the variable voltage control of actual inverters during faults. The 
correct identification of a fault can only be achieved after extensive fault transient analysis. In addition, identification techniques may fail due to the difficulty in obtaining synchronized measurement of all connection points in a PV array. Therefore, a fault location method using negativesequence voltage amplitude sparse measurements is considered for an unbalanced fault [92]. In this case, the faulty nodes are determined by an improved Bayesian compressive sensing algorithm used to recover the sparse fault current vector. This method is successfully tested on different unbalanced fault types, fault resistances, inverter controls and signal noise. The fault location is accurately and effectively determined without having synchronized measurements from all the nodes. A similar method for reliability evaluation of grid-connected PV systems with intermittent faults is designed based on dynamic Bayesian networks [93]. A Markov model with three states, no faults, intermittent faults and permanent faults, is compounded with Bayesian network. The effects of each fault including the fault coefficients, reliability and availability are investigated. The simulation results indicate that the reliability and availability of a central configuration with single inverter is less strong than a string or multi string configuration with multiple inverters. Also, much attention should be paid to improve the reliability and to prevent the possible failure of inverter components.

\section{Image Processing in PV Fault Diagnostics}

Applying satellite information and unmanned extra-terrestrial drone system based thermal image processing will potentially be the future for monitoring and diagnosis of PV systems faults. Fault detection performance is improved using satellite imaging by estimating the irradiance and DC power output [94]. In this case, the satellite data measurement for sunlight intensity is processed using fuzzy logic then compared with the ground measurement. From this information, the DC power is calculated to determine typical faults of PV systems. A similar satellite method has also been used to detect the fault condition of batteries that connected to the PV systems [95].

Aerial thermography with Unmanned Aerial Vehicles (UAV) is considered as a low-cost effective method for online surveillance of PV system performance [96]. The method can be considered as a useful and less time-consuming diagnostic method for PV plant performance compared with conventional fault diagnostic methods. In this research, detailed information about the technology of aerial thermographic measurements is explained in terms of general principles, important operational tools, new developments, and future trends. Sensors and instrumentation for on-line aerial inspection of PV plants are also included in the discussion.

A fault diagnosis method using infrared thermal imaging based on the crystalline silicon technology thermal response of PV modules subjected to common faults is reviewed [97]. The thermal image processing method is a new approach in PV system fault diagnosis (Figure 6). It will be a major topic for future discussion because of its cost-effectiveness and feasible technology. In implementing this method, a PV module is scanned using infrared thermography to create a surface thermal distribution [7]. Hotspot problems can be identified from a non-uniform temperature appearance. Such hotspots can potentially to cause damage to solar cell structures.

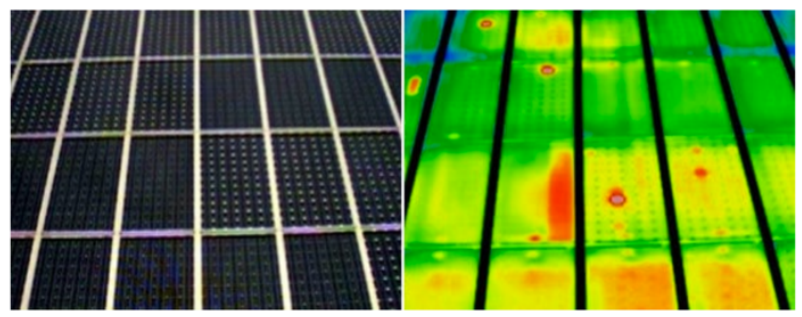

Fig. 6. Fault diagnosis of PV systems using infrared thermal imaging cameras

Courtesy: Avio Serviceizentrum Verkauf \& Schulung (NEC Group Company)

Another application of image processing to PV systems is the monitoring of PV panel performance after heavy rain and storm strikes. Heavy rain and storms may damage or completely break the glass cover or the solar cell itself. Such damage would lead to the loss of output power, system security, and safety of PV panels. After heavy hail attacks, potential hidden damage may be found through very careful PV inspection [98]. Of course, the damaged panel would need to be replaced. In this study, a PV monitoring system collects common data with thermographic sensors for further analysis. Further investigation is performed using non-destructive methods with the aid of innovative characterization tools, such as outdoor electroluminescence and UV-fluorescence imaging. With this approach, the potential solar cell damage caused by the mechanical stress of a hail storm can be detected even though the solar glass panel looks unbroken from visible eyes or the damage is not recognizable by thermal sensors. The proposed UV-fluorescence imaging method is easy to handle and can perform a fast characterization to detect partial cell breakage and/or microcracks in a solar cell.

\section{Summary}

In this paper, many aspects of photovoltaic (PV) fault diagnosis, detection and identification have been explored through an extensive study of recent literature. Various computational methods used in PV system analysis were investigated including the statistical and intelligent methods. Also, various fault diagnostic methods in PV systems were further investigated to show the willingness of researchers worldwide to solve the problems. Real-time monitoring systems were discussed as well as fault tolerance and performance in PV systems. As connecting PV systems to the grid is an important topic, a survey of diagnostic methods used in grid connected systems is also given. In other overview, the proposed systems based on various image processing techniques were summarized. In this respect, overall a comprehensive study of PV fault diagnostics systems was given. This summary should help spur further discussion and research on the subject.

\section{Acknowledgement}

This research is granted by the National Ministry of Research, Technology and Higher Education of Indonesia under Program of Scheme for Academic and Mobility Exchange (SAME) 2018.

This is an Open Access article distributed under the terms of the Creative Commons Attribution License 


\section{References}

[1] A.Mellit, G.M.Tina, S.A.Kalogirou, Fault detection and diagnosis methods for photovoltaic systems: A review, Renewable and Sustainable Energy Reviews, vol. 91, pp. 1-17, August 2018

[2] Elyes Garoudja, Fouzi Harrou, Ying Sun, Kamel Kara, Aissa Chouder, Santiago Silvestre, Statistical fault detection in photovoltaic systems, Solar Energy, vol. 150, pp. 485-499, 1 July 2017

[3] Chinedu I.Ossai, Optimal renewable energy generation Approaches for managing ageing assets mechanisms, Renewable and Sustainable Energy Reviews, vol. 72, pp. 269-280, May 2017

[4] Bechara Nehme, Nacer K.Msirdi, Aziz Namaane, Tilda Akiki, Analysis and Characterization of Faults in PV Panels, Energy Procedia, vol. 111, pp. 1020-1029, March 2017

[5] Shibo Lu, B.T. Phung, Daming Zhang, A comprehensive review on DC arc faults and their diagnosis methods in photovoltaic systems, Renewable and Sustainable Energy Reviews, vol. 89, pp. 88-98, June 2018

[6] M. Bressan, Y .El Basri, A. G. Galeano, C.Alonso, A shadow fault detection method based on the standard error analysis of I-V curves, Renewable Energy, vol. 99, pp. 1181-1190, December 2016

[7] Michael Simon, Edson L.Meyer, Detection and analysis of hot-spot formation in solar cells, Solar Energy Materials and Solar Cells, vol. 94, Issue 2, pp. 106-113, February 2010

[8] M. M. Alkaisi, N. A. Aldawody, Factors affecting the hot spot efficacity in photovoltaic arrays, Solar Cells, vol. 28, Issue 1, pp. 1117, January 1990

[9] He Wang, Ao Wang, Hong Yang, Jingsheng Huang, Study on the Thermal Stress Distribution of Crystalline Silicon Solar Cells in BIPV, Energy Procedia, vol. 88, pp. 429-435, June 2016

[10] Oussama Hachana, Giuseppe Marco Tina, Kamel Eddine Hemsas, PV array fault Diagnostic Technique for BIPV systems, Energy and Buildings, vol. 126, pp. 263-274, 15 August 2016

[11] Jack Flicker, Jay Johnson, Photovoltaic ground fault detection recommendations for array safety and operation, Solar Energy, vol. 140, pp. 34-50, 15 December 2016

[12] P.D.Moskowitz, E.A.Coveney, S.Rabinowitz, J.I.Barancik, Rooftop photovoltaic arrays: Electric shock and fire health hazards, Solar Cells, vol. 9, Issue 4, pp. 327-336, September 1983

[13] Siva Ramakrishna Madeti, S.N.Singh, A comprehensive study on different types of faults and detection techniques for solar photovoltaic system, Solar Energy, vol. 158, pp. 161-185, December 2017

[14] Alexander Phinikarides, Nitsa Kindyni, George Makrides, George E.Georghiou, Review of photovoltaic degradation rate methodologies, Renewable and Sustainable Energy Reviews, vol. 40, pp. 143-152, December 2014

[15] Siva Ramakrishna Madeti, S.N.Singh, Modeling of PV system based on experimental data for fault detection using $\mathrm{kNN}$ method, Solar Energy, vol. 173, pp. 139-151, October 2018

[16] Fouzi Harrou, Ying Sun, Bilal Taghezouit, Ahmed Saidi, MohamedElkarim Hamlati, Reliable fault detection and diagnosis of photovoltaic systems based on statistical monitoring approaches, Renewable Energy, vol. 116, Part A, pp. 22-37, February 2018

[17] Majdi Mansouri, Mansour Hajji, Mohamed Trabelsi, Mohamed Faouzi Harkat, Ayman Al-khazraji, Andreas Livera, Hazem Nounou, Mohamed Nounou, An effective statistical fault detection technique for grid connected photovoltaic systems based on an improved generalized likelihood ratio test, Energy, vol. 159, pp. 842-856, 15 September 2018

[18] Mahmoud Dhimish, Violeta Holmes, Fault detection algorithm for grid-connected photovoltaic plants, Solar Energy, vol. 137, pp. 236245, 1 November 2016

[19] Mahmoud Dhimish, Violeta Holmes, Bruce Mehrdadi, Mark Dales, The impact of cracks on photovoltaic power performance, Journal of Science: Advanced Materials and Devices, vol. 2, Issue 2, pp. 199209, June 2017

[20] W.Chine, A.Mellit, V.Lughi, A.Malek, G.Sulligoi, A.Massi Pavan, A novel fault diagnosis technique for photovoltaic systems based on artificial neural networks, Renewable Energy, vol. 90, pp. 501-512, May 2016

[21] H.Mekki, A.Mellit, H.Salhi, Artificial neural network-based modelling and fault detection of partial shaded photovoltaic modules, Simulation Modelling Practice and Theory, vol. 67, pp. 1-13, September 2016
[22] Adriana Alexandru, Adela Buzuloiu, Supervision and Diagnosis of Complex PV Power Systems, IFAC Proceedings Volumes, vol. 34, Issue 8, pp. 165-169, July 2001

[23] Rabah Benkercha, Samir Moulahoum, Fault detection and diagnosis based on C4.5 decision tree algorithm for grid connected PV system, Solar Energy, vol. 173, pp. 610-634, October 2018

[24] Zhicong Chen, Lijun Wu, Shuying Cheng, Peijie Lin, Yue Wu, Wencheng Lin, Intelligent fault diagnosis of photovoltaic arrays based on optimized kernel extreme learning machine and I-V characteristics, Applied Energy, vol. 204, pp. 912-931, 15 October 2017

[25] Abhik Hazra, Saborni Das, Mousumi Basu, An efficient fault diagnosis method for PV systems following string current, Journal of Cleaner Production, vol. 154, pp. 220-232, 15 June 2017

[26] Saborni Das, Abhik Hazra, Mousumi Basu, Metaheuristic optimization based fault diagnosis strategy for solar photovoltaic systems under non-uniform irradiance, Renewable Energy, vol. 118, pp. 452-467, April 2018

[27] Prakash K. Ray, Asit Mohanty, Basanta K. Panigrahi, Pravat K. Rout Modified wavelet transform based fault analysis in a solar photovoltaic system, Optik, vol. 168, pp. 754-763, September 2018

[28] il-SongKim, On-line fault detection algorithm of a photovoltaic system using wavelet transform, Solar Energy, vol. 126, pp. 137-145, March 2016

[29] A.Belaout, F.Krim, A.Mellit, B.Talbi, A.Arabi, Multiclass adaptive neuro-fuzzy classifier and feature selection techniques for photovoltaic array fault detection and classification, Renewable Energy, vol. 127, pp. 548-558, November 2018

[30] Kuei-Hsiang Chao, Chia-Lung Chiu, Ching-Ju Li, Yu-Choung Chang, A novel neural network with simple learning algorithm for islanding phenomenon detection of photovoltaic systems, Expert Systems with Applications, vol. 38, Issue 10, pp. 12107-12115, 15 September 2011

[31] Luca Bonsignore, Mehrdad Davarifar, Abdelhamid Rabhi, Giuseppe M.Tina, Ahmed Elhajjaji, Neuro-Fuzzy Fault Detection Method for Photovoltaic Systems, Energy Procedia, vol. 62, pp. 431-441, 2014

[32] Mahmoud Dhimish, Violeta Holmes, Bruce Mehrdadi, Mark Dales, Comparing Mamdani Sugeno fuzzy logic and RBF ANN network for PV fault detection, Renewable Energy, vol. 117, pp. 257-274, March 2018

[33] Sergiu Spataru, Dezso Sera, Tamas Kerekes, Remus Teodorescu, Diagnostic method for photovoltaic systems based on light $I-V$ measurements, Solar Energy, vol. 119, pp. 29-44, September 2015

[34] Mahmoud Dhimish, Violeta Holmes, Bruce Mehrdadi, Mark Dales, Peter Mather, Photovoltaic fault detection algorithm based on theoretical curves modelling and fuzzy classification system, Energy, vol. 140, Part 1, pp. 276-290, 1 December 2017

[35] Mahmoud Dhimish, Violeta Holmes, Bruce Mehrdadi, Mark Dales, Diagnostic method for photovoltaic systems based on six layer detection algorithm, Electric Power Systems Research, vol. 151, pp. 26-39, October 2017

[36] Guangyu Liu, Weijie Yu, Ling Zhu, Condition classification and performance of mismatched photovoltaic arrays via a pre-filtered Elman neural network decision making tool, Solar Energy, vol. 173, pp. 1011-1024, October 2018

[37] Yue Wu, Zhicong Chen, Lijun Wu, Peijie Lin, Shuying Cheng, Peimin Lu, An Intelligent Fault Diagnosis Approach for PV Array Based on SA-RBF Kernel Extreme Learning Machine, Energy Procedia, vol. 105, pp. 1070-1076, May 2017

[38] Majdi Mansouri, Ayman Al-khazraji, Mansour Hajji, Mohamed Faouzi Harkat, Hazem Nounou, Mohamed Nounou, Wavelet optimized EWMA for fault detection and application to photovoltaic systems, Solar Energy, vol. 167, pp. 125-136, June 2018

[39] Mahmoud Dhimish, Violeta Holmes, Mark Dales, Parallel fault detection algorithm for grid-connected photovoltaic plants, Renewable Energy, vol. 113, pp. 94-111, December 2017

[40] Louis L.Bucciarelli Jr., Power loss in photovoltaic arrays due to mismatch in cell characteristics, Solar Energy, vol. 23, Issue 4, pp. 277-288, 1979

[41] Nabil Kahoul, Mourad Houabes, Mohammed Sadok, Assessing the early degradation of hotovoltaic modules performance in the Saharan region, Energy Conversion and Management, vol. 82, pp. 320-326 June 2014 
[42] Suk Whan Ko, Young Chul Ju, Hye Mi Hwang, Jung Hun So, Young-Seok Jung, Hyung-Jun Song, Hee-eun Song, Soo-Hyun Kim, Gi Hwan Kang, Electric and thermal characteristics of photovoltaic modules under partial shading and with a damaged bypass diode, Energy, vol. 128, pp. 232-243, 1 June 2017

[43] Hanxiang Ding, Kun Ding, Jingwei Zhang, Yue Wang, Lie Gao, Yuanliang Li, Fudong Chen, Zhixiong Shao, Wanbin Lai, Local outlier factor-based fault detection and evaluation of photovoltaic system, Solar Energy, vol. 164, pp. 139-148, April 2018

[44] Guodeng Chen, Peijie Lin, Yunfeng Lai, Zhicong Chen, Lijun Wu, Shuying Cheng, Location for fault string of photovoltaic array based on current time series change detection, Energy Procedia, vol. 145, pp. 406-412, July 2018

[45] K.Djermouni, A.Berboucha, K.Ghedamsi, D.Aouzellag, Optimization of a photovoltaic field during faulty and normal operation, Solar Energy, vol. 113, pp. 171-180, March 2015

[46] Mahmoud Dhimish, Violeta Holmes, Bruce Mehrdadi, Mark Dales, Benjamin Chong, Li Zhang, Seven indicators variations for multiple PV array configurations under partial shading and faulty PV conditions, Renewable Energy, vol. 113, pp. 438-460, December 2017

[47] Sara Gallardo-Saavedra, Björn Karlsson, Simulation, validation and analysis of shading effects on a PV system, Solar Energy, vol. 170, pp. 828-839, August 2018

[48] S.K.Firth, K.J.Lomas, S.J.Rees, A simple model of PV system performance and its use in fault detection, Solar Energy, vol. 84, Issue 4, pp. 624-635, April 2010

[49] Mehdi Hosseinzadeh, Farzad Rajaei Salmasi, Determination of maximum solar power under shading and converter faults-A prerequisite for failure-tolerant power management systems, Simulation Modelling Practice and Theory, vol. 62, pp. 14-30, March 2016

[50] Nuri Gokmen, Engin Karatepe, Santiago Silvestre, Berk Celik, Pablo Ortega, An efficient fault diagnosis method for PV systems based on operating voltage-window, Energy Conversion and Management, vol. 73, pp. 350-360, September 2013

[51] Nuri Gokmen, Engin Karatepe, Berk Celik, Santiago Silvestre, Simple diagnostic approach for determining of faulted PV modules in string based PV arrays, Solar Energy, vol. 86, Issue 11, pp. 3364 3377 , November 2012

[52] Kuei-Hsiang Chao, Sheng-Han Ho, Meng-Hui Wang, Modeling and fault diagnosis of a photovoltaic system, Electric Power Systems Research, vol. 78, Issue 1, pp. 97-105, January 2008

[53] Yihua Hu, Bin Gao, Xueguan Song, Gui Yun Tian, Kongjing Li, Xiangning He, Photovoltaic fault detection using a parameter based model, Solar Energy, vol. 96, pp. 96-102, October 2013

[54] CristinaVentura, Giuseppe MarcoTina, Utility scale photovoltaic plant indices and models for on-line monitoring and fault detection purposes, Electric Power Systems Research, vol. 136, pp. 43-56, July 2016

[55] Siva Ramakrishna Madeti, S.N.Singh, Online fault detection and the economic analysis of grid-connected photovoltaic systems, Energy, vol. 134, pp. 121-135, 1 September 2017

[56] A.Drews, A.C.de Keizer, H.G.Beyer, E.Lorenz, J.Betcke, W.G.J.H.M.van Sark, W.Heydenreich, E.Wiemken, S.Stettler, P.Toggweiler, S.Bofinger, M.Schneider, G.Heilscher, D.Heinemann, Monitoring and remote failure detection of grid-connected PV systems based on satellite observations, Solar Energy, vol. 81, Issue 4, pp. 548-564, April 2007

[57] Asma Triki-Lahiani, Afef Bennani-Ben Abdelghani, Ilhem SlamaBelkhodja, Fault detection and monitoring systems for photovoltaic installations: A review, Renewable and Sustainable Energy Reviews, vol. 82, part 3, pp. 2680-2692, February 2018

[58] Antonio Faba, Stefano Gaiotto, Gabriele Maria Lozito, A novel technique for online monitoring of photovoltaic devices degradation, Solar Energy, vol. 158, pp. 520-527, December 2017

[59] Mohamed Hassan Ali, Abdelhamid Rabhi, Ahmed El Hajjaji, Giuseppe M.Tina, Real Time Fault Detection in Photovoltaic Systems, Energy Procedia, vol. 111, pp. 914-923, March 2017

[60] Kuei-Hsiang Chao, Chao-Ting Chen, A remote supervision fault diagnosis meter for photovoltaic power generation systems, Measurement, vol. 104, pp. 93-104, July 2017

[61] Ersan Kabalci, Yasin Kabalci, A wireless metering and monitoring system for solar string inverters, International Journal of Electrical Power \& Energy Systems, vol. 96, pp. 282-295, March 2018

[62] Yongfu Li, Peijie Lin, Haifang Zhou, Zhicong Chen, Lijun Wu, Shuying Cheng, Fengping Su, On-line Monitoring System Based on Open Source Platform for Photovoltaic Array, Energy Procedia, vol. 145, pp. 427-433, July 2018
[63] Santiago Silvestre, Llanos Mora-López, Sofiane Kichou, Francisco Sánchez-Pacheco, Manuel Dominguez-Pumar, Remote supervision and fault detection on OPC monitored PV systems, Solar Energy, vol. 137, pp. 424-433, 1 November 2016

[64] J.Solórzano, M.A.Egido, Automatic fault diagnosis in PV systems with distributed MPPT, Energy Conversion and Management, vol. 76, pp. 925-934, December 2013

[65] A.Chouder, S.Silvestre, Automatic supervision and fault detection of PV systems based on power losses analysis, Energy Conversion and Management, vol. 51, Issue 10, pp. 1929-1937, October 2010

[66] Massimiliano De Benedetti, Fabio Leonardi, Fabrizio Messina, Corrado Santoro, Athanasios Vasilakos, Anomaly detection and predictive maintenance for photovoltaic systems, Neurocomputing, vol. 310 , pp. 59-68, 8 October 2018

[67] Nadir Boutasseta, Messaoud Ramdani, Saad Mekhilef, Fault-tolerant power extraction strategy for photovoltaic energy systems, Solar Energy, vol. 169, pp. 594-606, 15 July 2018

[68] N.K.Gautam, N.D.Kaushika, Network analysis of fault-tolerant solar photovoltaic arrays, Solar Energy Materials and Solar Cells, vol. 69, Issue 1, pp. 25-42, August 2001

[69] Gelma Boneya Huka, Weixing Li, Pupu Chao, Simin Peng, A comprehensive LVRT strategy of two-stage photovoltaic systems under balanced and unbalanced faults, International Journal of Electrical Power \& Energy Systems, vol. 103, pp. 288-301, December 2018

[70] I.I.Perpinias, N.P.Papanikolaou, E.C.Tatakis, Fault ride through concept in low voltage distributed photovoltaic generators for various dispersion and penetration scenarios, Sustainable Energy Technologies and Assessments, vol. 12, pp. 15-25, December 2015

[71] Kheng Heong Oon, Chia Kwang Tan, A.H.A.Bakar, Hang Seng Che, H.Mokhlis, H.A.Illias, Establishment of fault current characteristics for solar photovoltaic generator considering low voltage ride through and reactive current injection requirement, Renewable and Sustainable Energy Reviews, vol. 92, pp. 478-488, September 2018

[72] Amit Dhoke, Rahul Sharma, Tapan Kumar Saha, PV module degradation analysis and impact on settings of overcurrent protection devices, Solar Energy, vol. 160, pp. 360-367, 15 January 2018

[73] M.C.Falvo, S.Capparella, Safety issues in PV systems: Design choices for a secure fault detection and for preventing fire risk, Case Studies in Fire Safety, vol. 3, pp. 1-16, May 2015

[74] Hermanus L.R.van der Walt, Ramesh C.Bansal, Raj Naidoo, PV based distributed generation power system protection: A review, Renewable Energy Focus, vol. 24, pp. 33-40, March 2018

[75] Dhanup S.Pillai, N.Rajasekar, A comprehensive review on protection challenges and fault diagnosis in PV systems, Renewable and Sustainable Energy Reviews, vol. 91, pp. 18-40, August 2018

[76] Zhihua Zhang, Peter Crossley, Lianghuan Li, A positive-sequencefault-component-based improved reverse power protection for spot network with PV, Electric Power Systems Research, vol. 149, pp. 102-110, August 2017

[77] Qing Xiong, Shengchang Ji, Xiaojun Liu, Xianyong Feng, Fan Zhang, Lingyu Zhu, Angelo L. Gattozzi, Robert E.Hebner, Detecting and localizing series arc fault in photovoltaic systems based on time and frequency characteristics of capacitor current, Solar Energy, vol. 170, pp. 788-799, August 2018

[78] Rahman Dashti, Mohsen Ghasemi, Mohammad Daisy, Fault location in power distribution network with presence of distributed generation resources using impedance based method and applying $\pi$ line model, Energy, vol. 159, pp. 344-360, 15 September 2018

[79] Subhashish Bhattacharya, Tapan Saha, M.J.Hossain, Fault contribution from large photovoltaic systems in building power supply networks, Journal of Building Engineering, vol. 5, pp. 222230, March 2016

[80] A.Bracale, P.Caramia, G.Carpinelli, A.R.Di Fazio, Modeling the three-phase short-circuit contribution of photovoltaic systems in balanced power systems, International Journal of Electrical Power \& Energy Systems, vol. 93, pp. 204-215, December 2017

[81] Tobias Neumann, István Erlich, Short Circuit Current Contribution of a Photovoltaic Power Plant, IFAC Proceedings Volumes, vol. 45, Issue 21, pp. 343-348, 2012

[82] N.I.Ahmad, M.Z.A.Ab-Kadir, M.Izadi, N.Azis, M.A.M.Radzi, N.H.Zaini, M.S.M.Nasir, Lightning protection on photovoltaic systems: A review on current and recommended practices, Renewable and Sustainable Energy Reviews, vol. 82, Part 1, pp. 1611-1619, February 2018

[83] Browh Serge Tekpeti, Xiaoning Kang, Xinghua Huang, Fault analysis of solar photovoltaic penetrated distribution systems including overcurrent relays in presence of fluctuations, International 
Journal of Electrical Power \& Energy Systems, vol. 100, pp. 517530, September 2018

[84] Ailson P.Moura, J.A. Peças Lopes, Adriano A.F.de Moura, Jean Sumaili, C.L.Moreira, IMICV fault analysis method with multiple PV grid-connected inverters for distribution systems, Electric Power Systems Research, vol. 119, pp. 119-125, February 2015

[85] Alessandra Colli, Failure mode and effect analysis for photovoltaic systems, Renewable and Sustainable Energy Reviews, vol. 50, pp. 804-809, October 2015

[86] Santiago Silvestre, Aissa Chouder, Engin Karatepe, Automatic fault detection in grid connected PV systems, Solar Energy, vol. 94, pp. 119-127, August 2013

[87] Santiago Silvestre, Advances in Renewable Energies and Power Technologies, Chapter 7-Strategies for Fault Detection and Diagnosis of PV Systems, vol 1: Solar and Wind Energies, pp. 231255,2018

[88] Maria Malvoni, Maria Grazia De Giorgi, Paolo Maria Congedo, Study of degradation of a grid connected photovoltaic system, Energy Procedia, vol. 126, pp. 644-650, September 2017

[89] Siva Ramakrishna Madeti, S.N.Singh, Online modular level fault detection algorithm for grid-tied and off-grid PV systems, Solar Energy, vol. 157, pp. 349-364, 15 November 2017

[90] W.Chine, A.Mellit, A.Massi Pavan, S.A.Kalogirou, Fault detection method for grid-connected photovoltaic plants, Renewable Energy, vol. 66, pp. 99-110, June 2014

[91] Santiago Silvestre, Mário Aires daSilva, Aissa Chouder, Daniel Guasch, Engin Karatepe, New procedure for fault detection in grid connected PV systems based on the evaluation of current and voltage indicators, Energy Conversion and Management, vol. 86, pp. 241249 , October 2014
[92] Ke Jia, Chenjie Gu, Lun Li, Zhengwen Xuan, Tianshu Bi, David Thomas, Sparse voltage amplitude measurement based fault location in large-scale photovoltaic power plants, Applied Energy, vol. 211, pp. 568-581, 1 February 2018

[93] Baoping Cai, Yonghong Liu, Yunpeng Ma, Lei Huang, Zengkai Liu, A framework for the reliability evaluation of grid-connected photovoltaic systems in the presence of intermittent faults, Energy, vol. 93, Part 2, pp. 1308-1320, 15 December 2015

[94] Mohammed Tadj, Khalil Benmouiza, Ali Cheknane, Santiago Silvestre, Improving the performance of PV systems by faults detection using GISTEL approach, Energy Conversion and Management, vol. 80, pp. 298-304, April 2014

[95] Mohammed Tadj, Khalil Benmouiza, Ali Cheknane, An innovative method based on satellite image analysis to check fault in a PV system lead-acid battery, Simulation Modelling Practice and Theory, vol. 47, pp. 236-247, September 2014

[96] Sara Gallardo-Saavedra, Luis Hernández-Callejo, Oscar DuquePerez, Technological review of the instrumentation used in aerial thermographic inspection of photovoltaic plants, Renewable and Sustainable Energy Reviews, vol. 93, pp. 566-579, October 2018

[97] John A.Tsanakas, Long Ha, Claudia Buerhop, Faults and infrared thermographic diagnosis in operating c-Si photovoltaic modules: A review of research and future challenges, Renewable and Sustainable Energy Reviews, vol. 62, pp. 695-709, September 2016

[98] Wolfgang Muehleisen, Gabriele C.Eder, Yuliya Voronko, Markus Spielbergerc, Horst Sonnleitner, Karl Knoebl, Rita Ebner, Gusztav Ujvari, Christina Hirschl, Outdoor detection and visualization of hailstorm damages of photovoltaic plants, Renewable Energy, vol. 118, pp. 138-145, April 2018 